CHRONIC OBSTRUCTIVE PULMONARY DISEASE

\title{
Peripheral muscle endurance and the oxidative profile of the quadriceps in patients with COPD
}

\author{
J Allaire, F Maltais, J-F Doyon, M Noël, P LeBlanc, G Carrier, C Simard, J Jobin
}

Thorax 2004;59:673-678. doi: 10.1136/thx.2003.020636

See end of article for authors' affiliations

\section{Correspondence to:}

Dr J Jobin, Centre de recherches cliniques,

Hôpital Laval, 2725

Chemin Ste-Foy, Ste-Foy,

QC, Canada GIV 4G5;

jean.jobin@med.ulaval.ca

Received

20 December 2003

Accepted 18 April 2004
Background: Based on previously reported changes in muscle metabolism that could increase susceptibility to fatigue, we speculated that patients with chronic obstructive pulmonary disease (COPD) have reduced quadriceps endurance and that this will be correlated with the proportion of type I muscle fibres and with the activity of oxidative enzymes.

Methods: The endurance of the quadriceps was evaluated during an isometric contraction in 29 patients with COPD (mean (SE) age 65 (1) years; forced expiratory volume in 1 second 37 (3)\% predicted) and 18 healthy subjects of similar age. The electrical activity of the quadriceps was recorded during muscle contraction as an objective index of fatigue. The time at which the isometric contraction at $60 \%$ of maximal voluntary capacity could no longer be sustained was used to define time to fatigue (TF). Needle biopsies of the quadriceps were performed in 16 subjects in both groups to evaluate possible relationships between $\mathrm{TF}$ and markers of muscle oxidative metabolism (type I fibre proportion and citrate synthase activity).

Results: TF was lower in patients with COPD than in controls (42 (3) v 80 (7) seconds; mean difference 38 seconds (95\% Cl 25 to 50), $\mathrm{p}<0.001)$. Subjects in both groups had evidence of electrical muscle fatigue at the end of the endurance test. In both groups significant correlations were found between TF and the proportion of type I fibres and citrate synthase activity.

Conclusion: Isometric endurance of the quadriceps muscle is reduced in patients with COPD and the muscle oxidative profile is significantly correlated with muscle endurance.
$\mathrm{P}$ eripheral muscle dysfunction contributes to exercise intolerance in patients with chronic obstructive pulmonary disease (COPD). ${ }^{1-3}$ Evaluation of peripheral muscle strength and endurance is now frequently performed in pulmonary rehabilitation settings and exercise physiology laboratories. Previous reports have shown that peripheral muscle strength is reduced in COPD, ${ }^{12-4}$ an observation that has been attributed to muscle atrophy. ${ }^{45}$

Although earlier studies yielded conflicting results, ${ }^{67}$ it is becoming generally accepted that lower limb muscle endurance is reduced and susceptibility to fatigue is greater in patients with COPD than in healthy subjects of similar age. ${ }^{89}$ Poor peripheral muscle endurance is clinically relevant because it is associated with poor functional status ${ }^{7}$ and exercise intolerance in patients with COPD. ${ }^{10}$ Interestingly, endurance of the quadriceps does not seem to be associated with muscle mass in COPD. ${ }^{7}$ A more likely hypothesis is that quadriceps endurance in COPD should be linked to the aerobic capacity of the muscle rather than to its mass.

A study was undertaken to test the hypothesis that reduced quadriceps endurance in COPD is related to the proportion of type I muscle fibres and to the activity of oxidative enzymes rather than to mid thigh muscle cross sectional area. The endurance of the quadriceps was evaluated during an isometric contraction in 29 patients with COPD and 18 healthy subjects. Because the perception of muscle fatigue is subjective and the measurement of muscle endurance is effort dependent, muscle electrical activity was monitored during the endurance test as an objective assessment of muscle fatigue. Needle biopsies were performed in a subset of subjects to evaluate possible relationships between endurance time and markers of the muscle oxidative metabolism.

\section{METHODS}

\section{Subjects}

Twenty nine patients with COPD (20 men) participated in the study. The diagnosis of COPD was based on previous smoking history and pulmonary function tests showing moderate to severe bronchial obstruction (forced expiratory volume in l second $\left(\mathrm{FEV}_{1}\right)<60 \%$ of predicted and $\mathrm{FEV}_{1} /$ forced vital capacity (FVC) $<70 \%$ ). Subjects had no evidence of exercise limiting neuromuscular disorders. Patients had to be in a stable condition, with no exacerbation or use of corticosteroids in the preceding 2 months. Patients with COPD were studied before any involvement in pulmonary rehabilitation. The control group included 18 healthy subjects ( 15 men) not involved in regular exercise training. All subjects were retired and reported only low intensity leisure activities. The research protocol was approved by the institution's ethics committee and written informed consent was obtained in each case.

\section{Study protocol}

Pulmonary function tests

Standard pulmonary function tests including spirometry, lung volumes, and lung carbon monoxide transfer factor (TLCO) were performed in patients and healthy subjects according to previously described guidelines and related to normal values of Knudson, ${ }^{11}$ Goldman and Becklake, ${ }^{12}$ and Cotes and Hall, ${ }^{13}$ respectively.

Computed tomography of the thigh

A computed tomographic (CT) scan of the right thigh was performed halfway between the pubic symphysis and the inferior condyle of the femur using a 4th generation Toshiba
Abbreviations: $\mathrm{BMI}$, body mass index; $\mathrm{COPD}$, chronic obstructive pulmonary disease; $\mathrm{CS}$, citrate synthase; $\mathrm{FEV}_{1}$, forced expiratory volume in 1 second; FVC, forced vital capacity; $\mathrm{HADH}$, 3-hydroxyacyl $\mathrm{CoA}$ dehydrogenase; HK, hexokinase; LDH, lactate dehydrogenase; MT CSA, mid thigh muscle cross sectional area; MVC, maximal voluntary

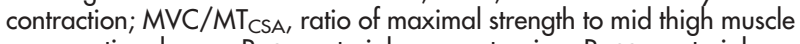 cross sectional area; $\mathrm{PaO}_{2}$, arterial oxygen tension; $\mathrm{PaCO}_{2}$, arterial carbon dioxide tension; PFK, phosphofructokinase; $\mathrm{SaO}_{2}$, arterial oxygen saturation; TF, time to fatigue; TLC, total lung capacity; TLCO, lung carbon monoxide transfer factor; $\mathrm{VO}_{2}$, oxygen consumption 
Scanner 900S. Images $10 \mathrm{~mm}$ thick were obtained with a scanning time of 1 second at $120 \mathrm{kV}$ and $200 \mathrm{~mA}$, with subjects in a supine position. The mid thigh muscle cross sectional area $\left(\mathrm{MT}_{\mathrm{CSA}}\right)$ was obtained by measuring the surface area of the tissue with a density of 40100 Hounsfield units (HU) corresponding to the range of density of muscle tissue. Analysis of all CT images was done blindly by the same radiologist.

\section{Muscle biopsy of the vastus lateralis}

Needle biopsies of the vastus lateralis muscle were performed at rest using a technique described by Bergström ${ }^{14}$ and routinely performed in our laboratory ${ }^{15}$ in 16 patients and 16 healthy subjects who accepted the procedure. Briefly, after local anaesthesia with lidocaine $2 \%$ a $1 \mathrm{~cm}$ incision was made and muscle samples were obtained. Muscle specimens were prepared and then immediately frozen in liquid nitrogen and stored at $-80^{\circ} \mathrm{C}$ until processing.

\section{Exercise testing}

All subjects performed a symptom limited progressive exercise test (Quinton Corival 400, A-H Robins, Seattle, WA, USA). After 5 minutes of resting, a progressive and symptom limited stepwise exercise test was performed while breathing room air (Quinton Qplex, A-H Robins). Each exercise step lasted 1 minute and increments of 10 or 20 watts were used in COPD and healthy subjects, respectively. Peak oxygen consumption in absolute and predicted values ${ }^{16}$ were used as the index of peak exercise capacity.

\section{Peripheral muscle function}

Twenty to 48 hours after the exercise test, maximal voluntary contraction (MVC) and endurance of the right quadriceps muscle were evaluated using a semi-recumbent chair (HFstar, Henley Healthcare Belton, TX, USA) equipped with a strain gauge (Hewlett-Packard, Palo Alto, CA, USA) to measure isometric knee extension tension. Exercise was performed with knee and hip angles of approximately $120^{\circ}$. The obtained signal was amplified (8811A amplificator, Hewlett-Packard), then transformed by an analogue transducer (Biopac system, Santa Barbara, CA, USA) connected to a computer for data analysis (Acknowledge software, Biopac). In order to determine their MVC, subjects performed three brief maximal contractions separated by resting periods of 2 minutes. If maximal values maintained for 2 seconds were reproducible $(<10 \%$ variability), the highest value of these three contractions was considered as the MVC. In case of an MVC variability of $>10 \%$ we had planned to ask participants to perform a fourth manoeuvre but this was unnecessary since all participants were able to produce two reproducible maximal contractions in their first three attempts.

Muscle endurance was evaluated using an adaptation of a protocol previously described by Viitasalo and Komi. ${ }^{17}$ After 10 minutes of rest following the MVC manoeuvres, subjects were instructed to maintain a tension representing $60 \%$ of their MVC until exhaustion. A computer screen served as a feedback mechanism to help subjects maintain the determined submaximal tension. Subjects were strongly encouraged to pursue until tension dropped to 50\% MVC. Peripheral muscle endurance was thus assessed by the time to fatigue $(\mathrm{TF})$, defined as the time at which the isometric contraction reached 50\% MVC.

\section{Surface electromyography}

During the evaluation of $\mathrm{TF}$, bipolar surface electromyography (EMG) was recorded from the right vastus lateralis muscle halfway between greater trochanter and lateral condyle, within $3 \mathrm{~cm}$ from the biopsy site. Inter-electrodes impedance was lowered to a maximum of $4 \mathrm{k} \Omega$ (Quick-Prep, Quinton, A H Robbins) and the same Biopac system was used for amplification, band pass filtering $(8-250 \mathrm{~Hz})$, recording, and analysis of the EMG signal. Samples of 2 seconds were analysed at times corresponding to $0,25,50,75$, and $100 \%$ TF. Comparison of the EMG signal between groups was thus made at the same relative times. The median frequency of the signal was derived from a Fast-Fourier transform analysis. This EMG parameter was preferred to mean frequency because it is less susceptible to signal noise. ${ }^{18}$ Although no clear cut off has been proposed, a spectral compression toward lower frequencies during a sustained isometric contraction is considered as evidence of fatigue. ${ }^{19}$

\section{Muscle biopsy analyses}

\section{Fibre typing}

Frozen samples were embedded in OCT compound (TissueTek, Miles Inc, Elkhart, IN, USA) and transverse sections of $10 \mu \mathrm{m}$ were cut using a cryostat Leica Jung CM 3000 (Wetzlar, Germany). Each section was verified by light microscopy to ensure proper fibre orientation. Muscle sections were stained for myofibrillar adenosine triphosphatase (mATPase) activity according to the single step ethanol modified technique, as previously described. ${ }^{20}$ Depending on the staining intensity, the different fibre types were designated as type I (non-stained), type IIa (lightly stained), and type IIx (darkly stained). The staining intensity of fibres intermediate between IIa and IIx were classified as IIax.

\section{Enzymology}

Activities of citrate synthase (CS, EC 4.1.3.7), 3-hydroxyacyl CoA dehydrogenase (HADH, EC 1.1.1.35), hexokinase (HK, EC 2.7.1.1), lactate dehydrogenase (LDH, EC 1.1.1.27), and phosphofructokinase (PFK, EC 2.7.1.11) were evaluated with a spectrophotometric technique, as previously described. ${ }^{15}$

\section{Statistical analyses}

Values are reported as mean (SE). According to the data distribution, comparisons between groups were done with unpaired Student's $t$ test or Wilcoxon rank sum test. The normality assumption was verified with the Shapiro-Wilk test and Brown and Forsythe's variation of Levene's test statistic was used to verify homogeneity of variances. The split plot design was used to analyse the EMG data. Two experimental factors-one comparing COPD and controls and one taking into account the time periods during the endurance test $(0,25,50,75$ and $100 \% \mathrm{TF})$-were included in the analysis. A mixed model analysis was performed with an interaction term between these two factors. Pearson's correlation coefficients were used to evaluate possible relationships between $\mathrm{TF}_{\mathrm{F}}$, muscle mass, fibre type distribution, and enzymatic activities. A $p$ value of $<0.05$ was considered statistically significant. Data were analysed using the statistical package program SAS version 8.2 (SAS Institute Inc, Cary, NC, USA).

\section{RESULTS}

\section{Characteristics of subjects}

The characteristics of the study subjects are shown in table 1 . Both groups were similar for age and body mass index. Patients had, on average, severe irreversible obstruction (post-bronchodilator improvement in $\mathrm{FEV}_{1}<15 \%$ prebronchodilator value), with a mean $\mathrm{FEV}_{1}$ of 37 (3)\% of the predicted value and an $\mathrm{FEV}_{1} / \mathrm{FVC}$ ratio of $43(2) \%$. Patients also had mild reductions in resting $\mathrm{PaO}_{2}$ and $\mathrm{SaO}_{2}$ and normal $\mathrm{PaCO}_{2}$. Exercise capacity was also decreased in patients with COPD with a peak oxygen consumption of 14 (1) $\mathrm{ml} / \mathrm{kg} / \mathrm{min}$ compared with $28(2) \mathrm{ml} / \mathrm{kg} / \mathrm{min}$ in healthy subjects (mean 
Table 1 Characteristics of study subjects

\begin{tabular}{|c|c|c|c|c|}
\hline & $\begin{array}{l}\text { COPD } \\
(n=29)\end{array}$ & $\begin{array}{l}\text { Healthy subjects } \\
(\mathrm{n}=18)\end{array}$ & $\begin{array}{l}\text { Mean difference } \\
(95 \% \mathrm{Cl})\end{array}$ & $p$ value \\
\hline $\begin{array}{l}\text { Age (years) } \\
\mathrm{BMI}\left(\mathrm{kg} / \mathrm{m}^{2}\right) \\
\mathrm{FEV}_{1}(\mathrm{l}) \\
\mathrm{FEV}_{1}(\% \text { pred) } \\
\mathrm{FVC}(\mathrm{l}) \\
\mathrm{FVC}(\% \text { pred) } \\
\mathrm{TLC}(\% \text { pred) } \\
\mathrm{TLCO}(\% \text { pred) } \\
\text { Resting } \mathrm{PaO}_{2}(\mathrm{kPa}) \\
\text { Resting } \mathrm{PaCO}_{2}(\mathrm{kPa}) \\
\text { Resting } \mathrm{SaO}_{2}(\%) \\
\text { Peak } \mathrm{VO}_{2}(\mathrm{ml} / \mathrm{kg} / \mathrm{min}) \\
\text { Peak } \mathrm{VO}_{2}(\% \mathrm{pred})^{*}\end{array}$ & $\begin{array}{l}65(1) \\
25(1) \\
0.94(0.09) \\
37(3) \\
2.19(0.15) \\
59(3) \\
124(4) \\
56(6) \\
10.4(0.3) \\
5.6(0.1) \\
95(0) \\
14(1) \\
66(6)\end{array}$ & $\begin{array}{l}62(1) \\
26(1) \\
2.86(0.07) \\
110(4) \\
3.82(0.11) \\
101(4) \\
99(3) \\
111(3) \\
12.8(0.4) \\
5.2(0.1) \\
98(0) \\
28(2) \\
103(6)\end{array}$ & $\begin{array}{l}3(-1 \text { to } 7) \\
1(-2 \text { to } 5) \\
1.91(1.61 \text { to } 2.22) \\
72(63 \text { to } 82) \\
1.63(1.12 \text { to } 2.14) \\
42(32 \text { to } 52) \\
24(10 \text { to } 38) \\
54(35 \text { to } 73) \\
2.4(1.1 \text { to } 3.6) \\
0.4(-0.2 \text { to } 1.0) \\
3(1 \text { to } 4) \\
14(10 \text { to } 18) \\
37(18 \text { to } 55)\end{array}$ & $\begin{array}{l}\text { NS } \\
\text { NS } \\
<0.001 \\
<0.001 \\
<0.001 \\
<0.001 \\
<0.01 \\
<0.001 \\
<0.001 \\
\text { NS } \\
<0.001 \\
<0.001 \\
<0.001\end{array}$ \\
\hline \multicolumn{5}{|c|}{ 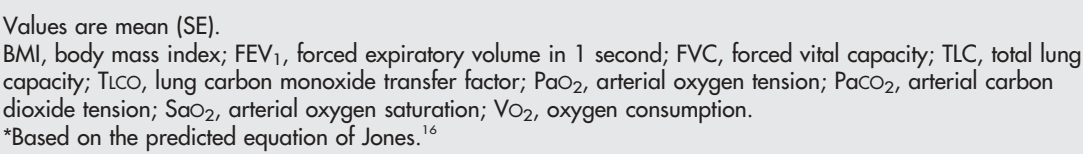 } \\
\hline
\end{tabular}

difference: $14 \mathrm{ml} / \mathrm{kg} / \mathrm{min}$ (95\% CI 10 to 18 ), $\mathrm{p}<0.001$ ). The baseline characteristics of subjects who accepted and those who did not accept the biopsy were similar (data not shown).

\section{Peripheral muscle function, morphology and enzymology}

Muscle mass, strength and endurance

Patients with COPD had muscle atrophy as indicated by a $\mathrm{MT}_{\mathrm{CSA}}$ of $66(3) \mathrm{cm}^{2}$ compared with $107(3) \mathrm{cm}^{2}$ for healthy subjects (mean difference $41 \mathrm{~cm}^{2}$ (95\% CI 31 to 52 ), $\mathrm{p}<0.001$, table 2). As expected, the strength of the quadriceps was also lower in patients than in healthy subjects (mean difference $17 \mathrm{~kg}(95 \%$ CI 10 to 23), p<0.001). Quadriceps isometric endurance was decreased in COPD, as shown by a mean TF of 42 (3) seconds compared with 80 (7) seconds in healthy subjects (mean difference 38 seconds (95\% CI 25 to 50), $\mathrm{p}<0.001)$.

\section{Myoelectrical signs of fatigue}

Figure 1 shows the time courses of the median frequence of the EMG signal of both groups during the fatigue test. Two patterns in the EMG median frequency were found at rest in the healthy subjects explaining its large variability in this group; in nine of 18 healthy subjects the resting EMG median frequency was in the COPD range $(140 \mathrm{~Hz})$ whereas in the other half of this group it was much lower $(90 \mathrm{~Hz})$. Although the mean EMG median frequencies were higher in patients with COPD, both groups showed the same pattern of change in EMG median frequency over time. At the end of the isometric contraction test both groups showed a significant fall in the EMG median frequency compared with resting values $(p<0.001)$ consistent with a fatiguing muscle contraction pattern. The slope of the fall in the EMG median frequency over time was similar in both groups but, because of a longer quadriceps isometric endurance test in the healthy

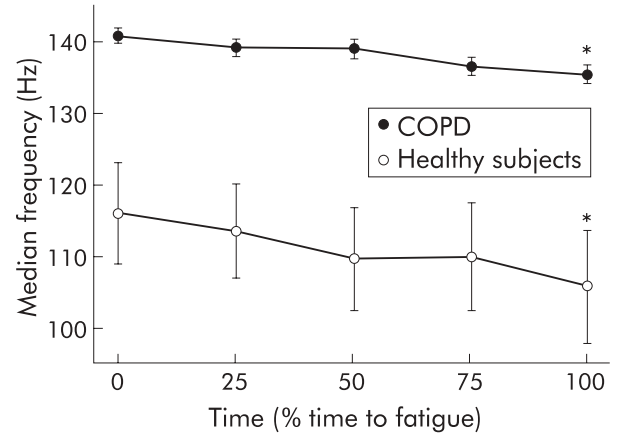

Figure 1 Time course of the EMG median frequency during the isometric contraction in patients with COPD (closed circles) and healthy subjects (open circles). The time is expressed as \% of time to fatigue (TF) and the median frequency in absolute value $(\mathrm{Hz})$. A significant decrease in the EMG median frequency was found in both groups. ${ }^{*}$ Time at which median frequency differed significantly from the initial value. Mean values with standard errors (bars) are shown.

subjects, the absolute fall was greater in the control group than in the COPD group (10 (2)\% $v 4(1) \%$, mean difference $6 \%(95 \%$ CI 2 to 10$), \mathrm{p}<0.001)$.

\section{Muscle morphology and enzymology}

Group mean values for fibre type composition and enzyme activities of the vastus lateralis are shown in table 3 . Compared with healthy subjects, patients with COPD had a marked reduction in the proportion of type I fibres (mean difference $31 \%$ (95\% CI 20 to 41 ), p < 0.001 ) with an increased proportion of type IIx fibres (mean difference 14\% (95\% CI 2 to 26$), \mathrm{p}<0.05$ ). The activity of the two oxidative enzymes (CS, HADH) was lower in the COPD group than in the control group (mean difference $3.8 \mu \mathrm{mol} / \mathrm{min} / \mathrm{g}$ (95\% CI 1.4 to 6.2 ),

Table 2 Peripheral muscle mass and strength

\begin{tabular}{lllll}
\hline & $\begin{array}{l}\text { COPD } \\
(\mathbf{n = 2 9 )}\end{array}$ & $\begin{array}{l}\text { Healthy subjects } \\
(\mathbf{n}=18)\end{array}$ & $\begin{array}{l}\text { Mean difference } \\
(\mathbf{9 5 \%} \mathrm{Cl})\end{array}$ & p value \\
\hline $\mathrm{MT}_{\mathrm{CSA}}\left(\mathrm{cm}^{2}\right)$ & $66(3)$ & $107(3)$ & $41(31$ to 51$)$ & $<0.001$ \\
$\mathrm{MVC}(\mathrm{kg})$ & $28(2)$ & $45(3)$ & $17(10$ to 23$)$ & $<0.001$ \\
$\mathrm{MVC} / \mathrm{MT}_{\mathrm{CSA}}\left(\mathrm{kg} / \mathrm{cm}^{2}\right)$ & $0.41(0.02)$ & $0.43(0.02)$ & $0.02(-0.04$ to 0.07$)$ & $\mathrm{NS}$ \\
$\mathrm{TF}$ (seconds) & $42(3)$ & $80(7)$ & $38(25$ to 50$)$ & $<0.001$ \\
\hline
\end{tabular}

Values are mean (SE).

$\mathrm{MT}_{\mathrm{CSA}}$, mid thigh muscle cross sectional area; MVC, maximal voluntary contraction; $M V C / M_{C S A}$, ratio of maximal strength to mid thigh muscle cross sectional area; TF, time to fatigue. 
Table 3 Histochemistry and enzymology of peripheral muscle

\begin{tabular}{|c|c|c|c|c|}
\hline & $\begin{array}{l}\text { COPD } \\
(n=16)\end{array}$ & $\begin{array}{l}\text { Healthy subjects } \\
(n=16)\end{array}$ & $\begin{array}{l}\text { Mean difference } \\
(95 \% \mathrm{Cl})\end{array}$ & p value \\
\hline \multicolumn{5}{|c|}{ Relative proportion of fibre (\%) } \\
\hline Type I & $27(3)$ & $58(3)$ & $31(20$ to 41$)$ & $<0.001$ \\
\hline Type lla & $32(4)$ & $29(3)$ & $2(-11$ to 15$)$ & NS \\
\hline Type Ilx & $22(4)$ & $8(2)$ & $14(2$ to 26$)$ & $<0.05$ \\
\hline Type llax & $19(1)$ & $5(1)$ & $3.8(-2$ to 10$)$ & NS \\
\hline \multicolumn{5}{|c|}{ Enzyme activities $(\mu \mathrm{mol} / \mathrm{min} / \mathrm{g})$} \\
\hline CS & $23.7(0.5)$ & $27.6(0.8)$ & $3.8(1.4$ to 6.2$)$ & $<0.01$ \\
\hline HADH & $5.0(0.2)$ & $6.8(0.4)$ & $1.8(0.7$ to 2.9$)$ & $<0.01$ \\
\hline $\mathrm{HK}$ & $1.5(0.1)$ & $1.7(0.1)$ & $0.2(-0.1$ to 0.5$)$ & NS \\
\hline $\mathrm{LDH}$ & $167.7(13.3)$ & $146.9(16.1)$ & $20(-28$ to 70$)$ & NS \\
\hline PFK & $71.8(6.6)$ & $38.1(2.8)$ & $33.6(14$ to 52$)$ & $<0.001$ \\
\hline \multicolumn{5}{|c|}{$\begin{array}{l}\text { Values are mean (SE). } \\
\text { CS, citrate synthase; HADH, 3-hydroxyacyl CoA dehydrogenase; HK, hexokinase; LDH, lactate dehydrogenase; } \\
\text { PFK, phosphofructokinase. }\end{array}$} \\
\hline
\end{tabular}

$\mathrm{p}<0.01$ for CS; mean difference $1.8 \mu \mathrm{mol} / \mathrm{min} / \mathrm{g}$ (95\% CI 0.7 to 2.9 ), $\mathrm{p}<0.01$ for $\mathrm{HADH}$ ). No significant differences were found for HK and LDH, while PFK activity was significantly higher in the COPD group (mean difference $33.6 \mu \mathrm{mol} / \mathrm{min} / \mathrm{g}$ $(95 \%$ CI 14 to 52$), \mathrm{p}<0.001)$.

\section{Correlation coefficients}

MVC correlated strongly with $\mathrm{MT}_{\mathrm{CSA}}$ in COPD $(r=0.77$, $\mathrm{p}<0.001)$ and in healthy subjects $(r=0.83, \mathrm{p}<0.001)$. A similar relationship between $\mathrm{TF}$ and $\mathrm{MT}_{\mathrm{CSA}}$ was seen in healthy subjects $(r=0.48, \mathrm{p}=0.05)$ but not in patients with COPD $(r=-0.13, \mathrm{p}=\mathrm{NS})$. TF correlated significantly with the proportion of type I muscle fibres of the vastus lateralis in healthy subjects $(r=0.50, \mathrm{p}<0.05$, fig $2 \mathrm{~A})$ and in patients with COPD $(r=0.74, \mathrm{p}<0.01$, fig $2 \mathrm{~B})$. Significant correlation coefficients could also be established between $\mathrm{TF}$ and CS activity in both groups (healthy subjects: $r=0.65$; $\mathrm{p}<0.01$; COPD subjects: $r=0.60, \mathrm{p}<0.05$, fig $2 \mathrm{C}$ and $\mathrm{D}$ ), but no relationship was observed with the other enzymes. TF did not correlate with any parameter of lung function.
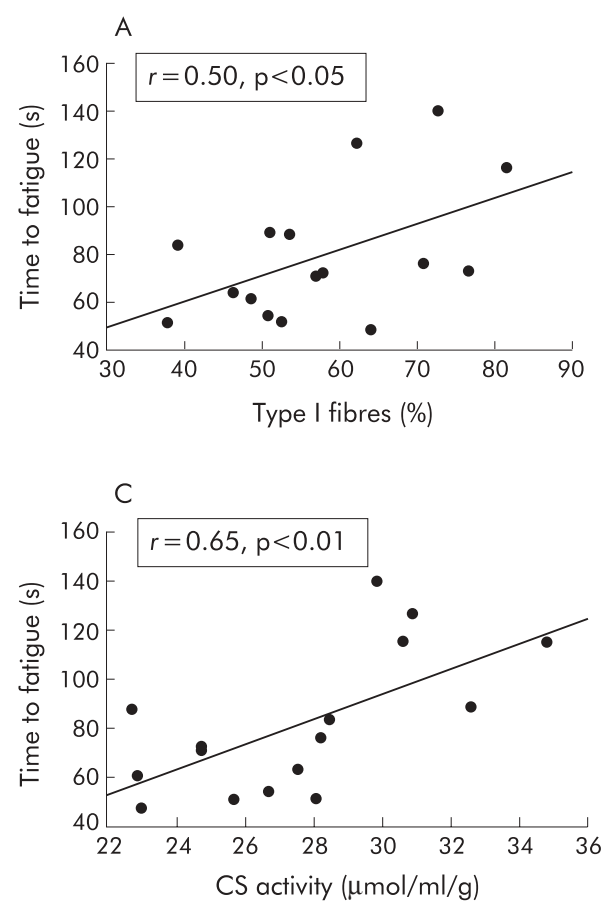

\section{DISCUSSION}

The results of this study indicate that quadriceps endurance is decreased in patients with COPD compared with healthy subjects and that the endurance of this muscle is not related to muscle mass but rather to muscle oxidative capacity. Furthermore, neuromuscular signs of fatigue were found in patients with COPD and in controls at the end of the muscle endurance test suggesting that, similarly to healthy subjects, patients with COPD can sustain a submaximal isometric contraction for a sufficient period of time to develop peripheral muscle fatigue.

To minimise the impact of the muscle contractions on the cardiopulmonary systems, an endurance protocol based on localised isometric contractions was used. During an isometric contraction performed at $60 \%$ of the maximum strength, the increase in intramuscular pressure will lead to a reduction in muscle blood flow thus restricting the demand placed on the heart. ${ }^{21}$ Apart from possible stimulation originating from the muscle metaboreceptors, ${ }^{22}$ the ventilatory requirement related to this exercise should remain
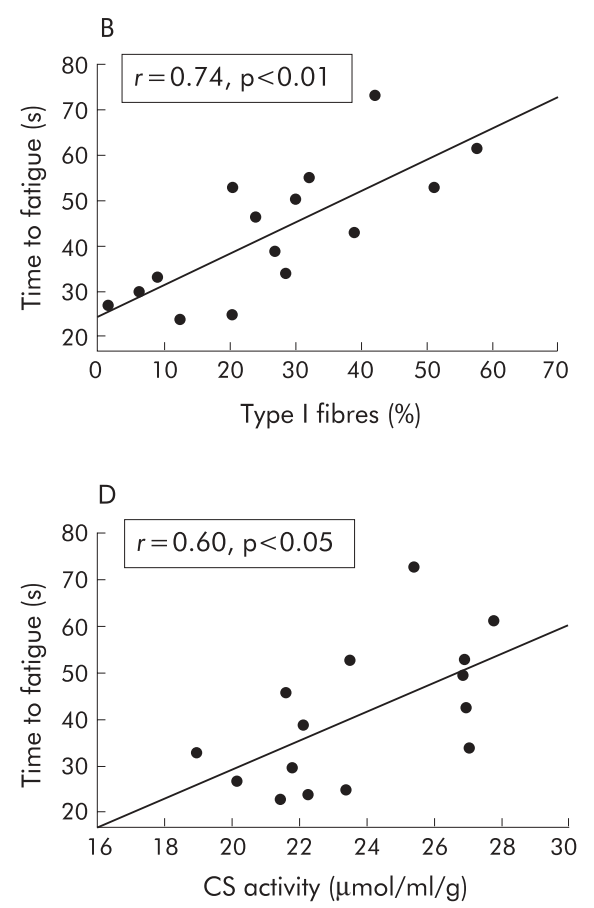

Figure 2 Relationship between time to fatigue (TF) and the proportion of type I fibres in (A) healthy subjects and (B) patients with COPD; and citrate synthase (CS) activitiy in (C) healthy subjects and (D) patients with COPD. A significant correlation was found between both parameters in both groups. 
modest due to the small muscle mass involved and to the fact that the muscle byproducts generated during such contraction will remain trapped locally. Although ventilation was not measured, it should be noted that none of the subjects reported an increase in dyspnoea during the endurance test. It is thus apparent that an isolated muscle isometric contraction could be sustained by patients with severe ventilatory limitation (such as those involved in the present study) for a sufficient length of time to develop muscle fatigue. These concepts were supported by the fact that EMG evidence of fatigue was found in patients with COPD and by the lack of correlation between $\mathrm{TF}$ and lung function.

One important aspect of this study is that an objective assessment of muscle fatigue was used. Changes in the EMG power spectrum have been studied extensively to assess muscle fatigue. Concomitantly with the development of muscle fatigue, there are changes in the power spectrum of the EMG signals with a relative decrease in the higher frequencies as evidenced by the decrease in EMG median frequency. ${ }^{19}$ The EMG frequency shift found in the fatiguing muscle has been attributed to the decrease in muscle fibre conduction velocity, ${ }^{18}$ as well as to lowering of muscle $\mathrm{pH}$ and to the progressive recruitment of type I fibres which have a lower frequency than type II fibres. Based on this information, the significant reduction in the EMG median frequency found in patients with COPD and in controls is indicative of a fatiguing muscle contraction pattern, although it cannot be ascertained whether this was the limiting factor during the endurance test. In fact, the greater absolute fall in EMG median frequency in healthy subjects than in those with COPD $(10 \% \vee 4 \%)$ suggests that it was not this EMG phenomenon that was directly responsible for the task failure in COPD. The ability to sustain a given contraction is a complex phenomenon being influenced by various factors such as the recruitment of additional motoneurone units during the fatiguing task, motivation, and the tolerance to uncomfortable symptoms. Unless truly effort-independent indices of muscle fatigue are used, the relative contribution of all the factors involved in the ability to sustain a fatiguing task cannot be ascertained. The higher median frequency throughout the endurance test in patients with COPD is also consistent with a higher proportion of type II fibres, as indicated by the relationship between muscle fibre type composition and the values and/or rate of change of estimates of EMG variables during sustained isometric contractions. $^{23}$

Although a physical activity questionnaire was not used in the present study, the healthy subjects recruited for this study were retired, were not involved in regular exercise training, and reported only low intensity leisure activities. The best available objective assessment of their fitness level is their peak oxygen consumption which averaged 103\% of the predicted value, consistent with a healthy non-athletic group. The proportion of type I fibres found in this group (58 (3)\%) may raise some concerns about their training status. There is a large interindividual variability in the fibre type distribution in healthy subjects. For instance, in one large study the proportion of type I fibre in sedentary healthy subjects varied from $15 \%$ to $85 \%{ }^{24}$ This is consistent with our past experience with control groups in whom the proportion of type I fibre varied from $43 \%$ to $58 \% .{ }^{92}$ Importantly, this discussion about the level of activity and the training status of the control group does not invalidate the main finding of the present study which is that the quadriceps endurance is related to the aerobic status of the muscle, both in healthy subjects and those with COPD.

In patients with COPD the lower limb muscles are affected both in quantity and quality. Muscle weakness is the direct consequence of the loss in muscle mass ${ }^{5}$ which also leads to poor exercise capacity. As opposed to strength, muscle endurance does not appear to be related to muscle mass, as evidenced by the lack of a significant relationship between $\mathrm{TF}$ and mid thigh muscle cross sectional area. The absence of correlation between fat free mass and muscle endurance reported by Serres et al also supports this statement. ${ }^{7}$ The observed positive correlations between $\mathrm{T}_{\mathrm{F}}$ and the proportion of type I muscle fibres and citrate synthase activity rather indicate that the alteration in muscle oxidative metabolism found in $\mathrm{COPD}^{325}$ is one likely mechanism leading to poor muscle endurance in this disease. The impairment in muscle oxidative capacity found in COPD leads to higher reliance on anaerobic glycolysis, in rapid accumulation of metabolic byproducts such as lactate, and in early muscle acidosis-all contributing to premature muscle fatigue. ${ }^{26}{ }^{27}$ The same principles can be applied to healthy subjects in whom muscle endurance also correlated with the oxidative profile of the quadriceps. The significant correlation between muscle mass and endurance found in these individuals is unlikely to be a causal factor. We rather interpret this finding as indicating that better muscle mass and endurance are likely to be found concomitantly in fit individuals.

If we accept that greater muscle oxidative status should lead to better endurance, our findings may have important clinical relevance. Admittedly, a causal relationship between muscle oxidative status and endurance cannot be firmly established from our data. However, based on the previous observation that exercise training increases muscle oxidative capacity $^{28}$ and reduces muscle fatiguability ${ }^{29}$ in patients with COPD, it is tempting to establish a link between the two phenomena. Taken together, our study and those of others provide a strong physiological rationale for the use of exercise training in patients with COPD which should translate into greater muscle endurance and functional status.

The isometric contraction test was performed at the same relative intensity in all subjects. Considering that MVC in COPD averaged $65 \%$ of the value obtained in controls, the reduction in muscle endurance found in COPD would have been even more considerable had the endurance test been performed at the same absolute intensity in both groups. This may have important implications in carrying out the activities of daily living during which absolute rather than relative muscle efforts have to be performed.

In summary, this study provides further support to the hypothesis that lower limb muscle endurance is reduced in patients with COPD. Reduced peripheral muscle oxidative capacity may have important functional consequences since it is an important correlate of muscle endurance.

\section{ACKNOWLEDGEMENTS}

The authors thank Serge Simard for his statistical assistance and Marthe Bélanger and Marie-Josée Breton for their technical support.

\section{Authors' affiliations \\ J Allaire, F Maltais, J-F Doyon, M Noël, P LeBlanc, G Carrier, C Simard, \\ J Jobin, Centre de recherche, Hôpital Laval, Institut universitaire de Cardiologie et de Pneumologie de l'Université Laval, Université Laval, Québec, Canada}

This study was supported in part by an educational research grant form Bayer Corporation. FM is a research scholar of the Fonds de Recherche en Santé du Québec.

This work was presented in part at the annual meeting of the American College of Sports Medicine, St-Louis, Missouri, June 2002.

\section{REFERENCES}

1 Hamilton AL, Killian KJ, Summers E, et al. Muscle strength, symptom intensity and exercise capacity in patients with cardiorespiratory disorders. Am J Respir Crit Care Med 1995; 152:2021-31. 
2 Gosselink R, Troosters T, Decramer M. Peripheral muscle weakness contributes to exercise limitation in COPD. Am J Respir Crit Care Med $1996 ; 153: 976-80$.

3 Maltais F, Simard AA, Simard C, et al. Oxidative capacity of the skeletal muscle and lactic acid kinetics during exercise in normal subjects and in patients with COPD. Am J Respir Crit Care Med 1996;153:288-93.

4 Bernard S, Leblanc $P$, Whittom F, et al. Peripheral muscle weakness in patients with chronic obstructive pulmonary disease. Am J Respir Crit Care Med 1998; 158:629-34.

5 Debigaré $\mathrm{R}$, Côté $\mathrm{CH}$, Hould FS, et al. In vitro and in vivo contractile properties of the vastus lateralis muscle in males with COPD. Eur Respir 2003;21:273-8.

6 Zattara-Hartmann MC, Badier M, Guillot C, et al. Maximal force and endurance to fatigue of respiratory and skeletal muscles in chronic hypoxemic patients: the effects of oxygen breathing. Muscle Nerve 1995;18:495-502.

7 Serres I, Gautier V, Varray AL, et al. Impaired skeletal muscle endurance related to physical inactivity and altered lung function in COPD patients. Chest 1998; 113:900-5.

8 Mador MJ, Deniz O, Aggarwal A, et al. Quadriceps fatigability after single muscle exercise in patients with chronic obstructive pulmonary disease. Am J Respir Crit Care Med 2003;168:102-8.

9 Couillard A, Maltais F, Saey D, et al. Exercise-induced quadriceps oxidative stress and peripheral muscle dysfunction in patients with COPD. Am J Respir Crit Care Med 2003;167:1664-9.

10 Saey D, Debigaré R, LeBlanc $P$, et al. Contractile leg fatigue after cycle exercise: a factor limiting exercise in patients with COPD. Am J Respir Crit Care Med 2003;168:425-30.

11 Knudson RJ, Slatin RC, Lebowitz MD, et al. The maximal expiratory flowvolume curve. Normal standards, variability and effects of age. Am Rev Respir Dis 1976;113:587-600.

12 Goldman HI, Becklake MR. Respiratory function tests: normal values at median altitudes and the prediction of normal results. Am Rev Tuberc 1959:79:454-67.

13 Cotes JE, Hall AM. The transfer factors for the lung; normal values in adults. In: Arcangeli $\mathrm{P}$, eds. Normal values for respiratory function in man. Torino: Panminerva Medica, 1970:327-43.

14 Bergström J. Muscle electrolytes in man. Determination by neutron activation analysis on needle biopsy specimens. A study on normal subjects, kidney patients and patients with chronic diarrhoea. Scand J Clin Lab Invest 1962;14:1-110.
15 Maltais $F$, Leblanc $P$. Whittom $F$, et al. Oxidative enzyme activities of the vastus lateralis muscle and the functional status in patients with COPD. Thorax 2000;55:848-53

16 Jones NL. Clinical exercise testing, 3rd ed. Philadelphia: W B Saunders, 1988.

17 Viitasalo JH, Komi PV. Signal characteristics of EMG during fatigue. Eur J Appl Physiol Occup Physiol 1977;37:111-21.

18 Stulen FB, Deluca CJ. Frequency parameters of the myoelectric signal as a measure of muscle conduction velocity. IEEE Trans Biomed Eng $1981 ; 28: 515-23$.

19 Basmajian JV, De LuCa CJ. Muscle alive, 5th ed. New York: Williams \& Wilkins, 1985:125-7.

20 Mabuchi K, Sréter FA. Actomyosin ATPase II. Fibre typing by histochemical ATPase. Muscle Nerve 1980;3:233-9.

21 Mortimer JT, Kerstein MD, Magnusson R, et al. Muscle blood flow in the human biceps as a function of developed muscle force. Arch Surg $1971 ; 103: 376-7$

22 Clark AL, Poole-Wilson PA, Coats AJ. Exercise limitation in chronic heart failure: central role of the periphery. J Am Coll Cardiol 1996;28:1092-102.

23 Merletti R, Knaflitz M, Deluca CJ. Electrically evoked myolectric signals. Crit Rev Biomed Eng 1992; 19:293-340.

24 Simoneau JA, Bouchard C. Human variation in skeletal muscle fiber-type proportion and enzyme activities. Am J Physiol 1989;257:E567-72.

25 Whittom F, Jobin J, Simard PM, et al. Histochemical and morphological characteristics of the vastus lateralis muscle in COPD patients. Comparison with normal subjects and effects of exercise training. Med Sci Sports Exerc 1998;30:1467-74.

26 Kutsuzawa T, Shioya S, Kurita D, et al. ${ }^{31} \mathrm{P}-\mathrm{NMR}$ study of skeletal muscle metabolism in patients with chronic respiratory impairment. Am Rev Respir Dis 1992; 146:1019-24.

27 Mainwood GW, Renaud JM. The effect of acid-base balance on fatigue of skeletal muscle. Can J Physiol Pharmacol 1985:63:403-16.

28 Maltais F, Leblanc P, Simard C, et al. Skeletal muscle adaptation to endurance training in patients with chronic obstructive pulmonary disease. Am J Respir Crit Care Med 1996; 154:442-7.

29 Mador MJ, Kufel TJ, Pineda LA, et al. Effect of pulmonary rehabilitation on quadriceps fatiguability during exercise. Am J Respir Crit Care Med $2001 ; 163: 930-5$ 